\title{
Effect of antidepressants use in pregnancy on foetus development and adverse effects in newborns
}

\author{
Ewa Bałkowiec-Iskra' ${ }^{1}$, Dagmara M. Mirowska-Guzel' ${ }^{2}$, Mirosław Wielgoś3 \\ ${ }^{1}$ Chair and Department of Experimental and Clinical Pharmacology; Nowowiejska City Hospital, Warsaw, Poland \\ ${ }^{2}$ Chair and Department of Experimental and Clinical Pharmacology, Centre for Preclinical Research and Technology (CePT), \\ Medical University of Warsaw, Poland \\ 3 I Chair and Clinic of Gynecology and Obstetrics, Medical University of Warsaw, Poland
}

\begin{abstract}
Over the last few years, several reports on the safety of antidepressants use in pregnancy have been published. Studies concerning the adverse effects of exposure to selective serotonin reuptake inhibitors (SSRI) during pregnancy on the developing foetus have indicated an increased risk of various congenital malformations and untoward effects such as poor neonatal adaptation syndrome or persistent pulmonary hypertension, but there still remain inconsistencies between various study results. This paper aims at reviewing the literature on the risks of exposure to antidepressants during pregnancy. SSRIs are generally considered as first-line antidepressant treatment in pregnancy, as they are generally safe and effective. To minimize the teratogenic risks, pregnant women should receive the minimal effective dose of the medication. Depression during pregnancy must not be left untreated, and it should also be remembered that the condition may extend into the postpartum period.
\end{abstract}

Key words: antidepressants, pregnancy, foetus, newborn, adverse effect

\section{INTRODUCTION}

Affective disorders are amongst the most common mental health problems in women of childbearing potential. A life-changing situation such as pregnancy may trigger or intensify the symptoms of depression. Based on a systematic review of published studies, it was estimated that around $18 \%$ of women suffer from prenatal depression, while in around $19 \%$ of females the symptoms emerge within the first several weeks following delivery [1]. Failure to diagnose the disease has a negative impact both on the mother and the baby. It was indicated that depression was associated, inter alia, with pre-eclampsia, premature birth, low birth weight, failure to seek prenatal care, inadequate diet, harmful substance abuse and higher risk of hospitalization in neonatal intensive care unit $[2,3]$. It was also found that untreated maternal depression during pregnancy may lead to disturbed emotional development of the newborn, and may increase the risk of mental disorder in the future [4]. Moreover, cases of decreased density of grey matter were described in young children whose mothers had suffered from depression while pregnant [5]. Importantly, prenatal depression is challenged by a high frequency of suicidal attempts, reaching $20 \%$ in adolescent mothers [6]. Efficacious treatment of depression during pregnancy and puerperium prevents the above-mentioned events. Psychotherapy is the first-line treatment for mild to moderate depression and should be recommended to women who have access to a skilled practitioner, are willing to participate in psychotherapy sessions and for whom psychotherapy is financially available. However, in women with Major Depressive Disorder (MDD), especially with suicidal thoughts, pharmacotherapy should be introduced. According to the guidelines on the treatment of MDD during the perinatal period, published in 2009 by the American Association of Obstetricians and Gynaecologists, monotherapy and taking the lowest effective dose of antidepressants are recommended [7]. There are no antidepressant drug efficacy trials in depressed pregnant women, however, selective serotonin reuptake inhibitors (SSRIs) are the most frequently used in pregnant women. In Poland, there are

Corresponding author:

Dagmara M. Mirowska-Guzel

Chair and Department of Experimental and Clinical Pharmacology, Centre for Preclinical Research and Technology (CePT)

Medical University of Warsaw

Banacha St. 1B, 02-097 Warsaw, Poland

e-mail: mirdag@poczta.onet.pl 
six active substances (fluoxetine, fluvoxamine, sertraline, paroxetine, citalopram and escitalopram) registered, belonging to this group. However, it should be stressed, that each of them has many generics, which are available on the market under various names (for example, there are currently 17 drugs containing citalopram in the Register of Medicinal Products). Serotonin-norepinephrine reuptake inhibitors (SNRIs) have been used increasingly as an alternative to SSRIs in recent years [8]. The most popularly used SNRIs are venlafaxine and duloxetine. All the medicine belonging either to SSRIs or SNRIs are classified in Food and Drug Administration (FDA) pregnancy category $C$, with the exception of paroxetine, which is classified in D. Less is known about other available antidepressants (including bupropion, mirtazapine, trazodone or tricyclic antidepressants). However, it should be stressed, that FDA categories are based on the assessment of risk, as obtained in human and animal studies. Categories may not directly correspond with clinical safety but may simply result from the fact that human safety data are lacking. Moreover, drugs in the same category may differ in their risks to the foetus. For this reason in 2015 the FDA introduced new labelling, which contains three principal components: a clinical consideration section, a risk summary and a data section.

Over recent years, the number of pregnant patients on antidepressants has been on the increase, but there is still insufficient data to be able to unequivocally determine the risk of birth defects and other adverse effects associated with the use of antidepressant medications. Potential complications associated with SSRIs and SNRIs use in pregnancy include inter alia modest increased risk of spontaneous abortion, preterm birth and low birth weight, poor neonatal adaptation syndrome and persistent pulmonary hypertension [9]. Many studies show that a high proportion of women treated for depression discontinue treatment once they become pregnant due to safety concerns [10]. Moreover, the relapse rate of $68 \%$ in women with MDD who discontinued their drugs during the first trimester was reported [11]. The decision about using antidepressants during pregnancy must be precisely discussed with pregnant women. Selective serotonin reuptake inhibitors (SSRIs) are believed to manifest the most favourable risk-benefit balance, and are thus most commonly used in the treatment of depression, including the management of depression during pregnancy. According to a population based study, the most commonly prescribed SSRIs during pregnancy were drugs containing sertraline, citalopram, escitalopram and fluoxetine. Venlafaxine was most commonly used SNRI [12]. To date, they have been treated as a homogenous class of drugs in terms of their teratogenic potential, but over the past year, results of two studies have been published in the British Medical Journal, indicating a possible association between the use of some SSRIs in the first trimester and selected congenital malformations $[13,14]$.

This paper aims at presenting the current state of knowledge on the effect of antidepressants on foetal development and neonatal health.

\section{ANTIDEPRESSANT USE AND THE RISK OF CONGENITAL ANOMALIES}

The results of studies on the rate of major birth defects and antidepressant use in pregnancy are conflicting and inconsistent. Many studies show no direct association between the use of antidepressants and birth defects, especially cardiovascular malformations. The largest amount of available data concerns the safety of SSRIs, which are presently the most commonly used antidepressant medications [15]. The teratogenic effect of SSRIs may result from the direct impact of serotonin on the foetus. It plays a significant role in the differentiation of the myocardial cells and formation of the cardiac septa, which is why an increased amount of the neurotransmitter, resulting from the use of drugs that inhibit its reuptake, may be linked to cardiovascular defects [16]. Even though the drugs from that class all have similar indications and mechanisms of action, recent observations go to show that their teratogenic potential may be different (Tab. 1, 2). Fluoxetine and paroxetine are believed to be associated with the highest risk of birth defects $[13,14]$. However, the available information makes unequivocal assessment of the teratogenic effect of antidepressants impossible. Further observations are required, as is continued monitoring of drug-related adverse events.

In 2005, based on the available findings at the time, the FDA demanded that paroxetine be reclassified from pregnancy category $C$ to $D$, i.e. a stronger warning, in recognition of the evidence for the drug's risk to the foetus [17]. An observational study carried out in Canada, involving $1403 \mathrm{fe-}$ males, assessed the safety of paroxetine and other antidepressants. The mean dose administered was $22.4 \mathrm{~g} /$ day ( $27 \%$ of the patients reduced their dose immediately upon pregnancy confirmation, without consulting it with the attending physician), and the mean treatment duration was 64 days. Congenital anomalies were reported in $7.2 \%$ of the neonates born to mothers who had been using antidepressants during pregnancy (39\% of all study subjects were on paroxetine), with cardiac defects affecting $1.8 \%$ of them [18]. In a detailed analysis, it was demonstrated that birth defects occurred in $8 \%$ of the newborns who had been exposed to paroxetine prenatally, as compared to $6 \%$ of those exposed to different SSRIs or other antidepressants, whereas congenital heart defects developed in $2 \%$ and $1 \%$ of the newborns, respectively. It was thus demonstrated that the use of paroxetine, dosed at over $25 \mathrm{mg} /$ day, caused a statistically significant doubling of the risk of birth defects, 
Table 1. Studies which confirm an association between the use of SSRIs in the first trimester of pregnancy and an increased risk of birth defects (according to Byatt et al. [2])

\begin{tabular}{|c|c|c|c|}
\hline Publication & Study drug/drugs & $\begin{array}{l}\text { Number of subjects } \\
\text { on the study drug/ } \\
\text { /drugs }\end{array}$ & Results \\
\hline Wogelius et al. (2006) & $\begin{array}{l}\text { fluoxetine, citalopram, paroxetine, } \\
\text { sertraline }\end{array}$ & 1051 & $\begin{array}{l}\text { Increased risk of congenital anomalies, no association } \\
\text { between the use of SSRIs and development of specific } \\
\text { defects }\end{array}$ \\
\hline $\begin{array}{l}\text { Kallen, Otterbla, } \\
\text { Olausson (2007) }\end{array}$ & $\begin{array}{l}\text { citalopram, sertraline, fluoxetine, } \\
\text { paroxetine }\end{array}$ & 6555 & $\begin{array}{l}\text { Increased risk of congenital heart defects in children } \\
\text { exposed to paroxetine }\end{array}$ \\
\hline Cole et al. (2007) & paroxetine & 1835 & Increased number of birth defects \\
\hline Louik et al. (2007) & $\begin{array}{l}\text { fluoxetine, citalopram, paroxetine, } \\
\text { sertraline, fluvoxamine, venlafaxine, } \\
\text { escitalopram, bupropion }\end{array}$ & 9849 & $\begin{array}{l}\text { Increased risk of craniosynostosis and cardiac septal } \\
\text { defects in children exposed to sertraline; increased risk } \\
\text { of right ventricular outflow tract obstruction }\end{array}$ \\
\hline Berard et al. (2007) & $\begin{array}{l}\text { paroxetine, sertraline, citalopram, } \\
\text { fluoxetine, fluvoxamine, bupropion }\end{array}$ & 1403 & $\begin{array}{l}\text { Increased risk of major birth defect in children exposed } \\
\text { to paroxetine at the dose exceeding } 25 \mathrm{mg} / \text { day }\end{array}$ \\
\hline Alwas et al. (2007) & $\begin{array}{l}\text { citalopram, sertraline, fluoxetine, } \\
\text { paroxetine }\end{array}$ & 9622 & $\begin{array}{l}\text { Increased risk of anencephaly, craniosynostosis, and } \\
\text { omphalocele }\end{array}$ \\
\hline Merlob et al. (2009) & $\begin{array}{l}\text { sertraline, fluoxetine, paroxetine, } \\
\text { fluvoxamine, citalopram, } \\
\text { escitalopram }\end{array}$ & 235 & $\begin{array}{l}\text { Two-fold increase in the risk of asymptomatic congenital } \\
\text { heart defects in children exposed to SSRIs }\end{array}$ \\
\hline Pedersen et al. (2009) & $\begin{array}{l}\text { fluoxetine, citalopram, paroxetine, } \\
\text { sertraline }\end{array}$ & 1370 & $\begin{array}{l}\text { Increased risk of cardiac septal defects in children } \\
\text { exposed to sertraline and citalopram. }\end{array}$ \\
\hline Reis and Kallen (2010) & $\begin{array}{l}\text { SSRI, bupropion, trazodone, } \\
\text { venlafaxine, TCA, MAOI }\end{array}$ & 15017 & $\begin{array}{l}\text { Increased risk of birth defects in children exposed } \\
\text { to TCAs (clomipramine in particular) and fluoxetine, } \\
\text { increased risk of congenital heart defects in those } \\
\text { exposed to paroxetine, increased risk of hypospadias } \\
\text { in those exposed to SSRIs (paroxetine in particular), } \\
\text { and increased risk of polycystic kidneys in children } \\
\text { exposed to SSRIs }\end{array}$ \\
\hline Bakker et al. (2010) & paroxetine & 678 & Increased risk of cardiac septal defects \\
\hline Bakker et al. (2010) & fluoxetine & 178 & $\begin{array}{l}\text { Increased risk of congenital hypertrophic pyloric } \\
\text { stenosis }\end{array}$ \\
\hline Kornum et al. (2010) & $\begin{array}{l}\text { sertraline, fluoxetine, fluvoxamine, } \\
\text { paroxetine, citalopram, } \\
\text { escitalopram }\end{array}$ & 2062 & $\begin{array}{l}\text { Increased risk of birth defects, including congenital } \\
\text { cardiac anomalies; increased risk of atrial septal defects } \\
\text { in those exposed to sertraline }\end{array}$ \\
\hline Malm et al. (2011) & $\begin{array}{l}\text { fluoxetine, citalopram, paroxetine, } \\
\text { sertraline, escitalopram }\end{array}$ & 6881 & $\begin{array}{l}\text { Increased risk of ventricular defects in children exposed } \\
\text { to fluoxetine; increased risk of right ventricular outflow } \\
\text { tract obstruction in children exposed to paroxetine; } \\
\text { increased risk of neural tube defects in those exposed } \\
\text { to citalopram }\end{array}$ \\
\hline Reefhuis et al. (2015) & $\begin{array}{l}\text { fluoxetine, citalopram, paroxetine, } \\
\text { sertraline, escitalopram }\end{array}$ & 659 & $\begin{array}{l}\text { Increased risk of right ventricular outflow tract } \\
\text { obstruction and craniosynostosis following exposure to } \\
\text { fluoxetine; increased risk of anencephaly, atrial septal } \\
\text { defects, right ventricular outflow tract obstruction, } \\
\text { omphalocele and gastroschisis following exposure to } \\
\text { paroxetine }\end{array}$ \\
\hline Furu et al. (2015) & $\begin{array}{l}\text { sertraline, fluoxetine, fluvoxamine, } \\
\text { paroxetine, citalopram, } \\
\text { escitalopram, venlafaxine }\end{array}$ & 1357 & $\begin{array}{l}\text { Exposure to venlafaxine and SSRIs (with the exception } \\
\text { of escitalopram) linked to an increased risk of congenital } \\
\text { cardiac anomalies }\end{array}$ \\
\hline
\end{tabular}

including a triple high risk of cardiac defects. However, other studies indicate, that the risk of heart defects is low [19]. In a recently published analysis, encompassing a literature review and data from the United States National Birth Defects Prevention Study (NBDPS), a statistically significant association was demonstrated between the use of paroxetine in the first trimester of pregnancy and the occurrence of five out of the seven birth defects analysed (anencephaly, atrial septal defect, right ventricular outflow tract obstruction, omphalocele, and gastroschisis) [13]. It was demonstrated that the absolute risk of anencephaly, when on paroxetine in early pregnancy, rises from 2 to 7 per 10,000 births, and the risk of right ventricular outflow tract obstruction from 10 to 24 per 10,000 births. It was also confirmed that exposure to 
Table 2. Studies which do not confirm an association between the use of SSRIs in the first trimester of pregnancy and an increased risk of birth defects (according to Byatt et al. [2])

\begin{tabular}{|c|c|c|c|}
\hline Publication & Study drug/drugs & $\begin{array}{l}\text { Number of subjects on study } \\
\text { drug/drugs }\end{array}$ & Results \\
\hline Wen SW et al. (2006) & $\begin{array}{l}\text { fluoxetine, sertraline, paroxetine, } \\
\text { citalopram, fluvoxamine }\end{array}$ & 972 & $\begin{array}{l}\text { No association between the } \\
\text { studied SSRIs and the risk of } \\
\text { malformations }\end{array}$ \\
\hline Cole et al. (2007) & bupropion & 1213 & $\begin{array}{l}\text { No impact on the risk of } \\
\text { malformations }\end{array}$ \\
\hline Einarson et al. (2008) & paroxetine & 3379 & $\begin{array}{l}\text { No impact on the risk of } \\
\text { congenital cardiovascular } \\
\text { anomalies }\end{array}$ \\
\hline Ramos et al. (2008) & $\begin{array}{l}\text { SSRI, TCA, SNRI, bupropion, } \\
\text { mirtazapine, maclobemide, } \\
\text { trazodone, nefazodone }\end{array}$ & $\begin{array}{c}2329 \text { (189 with major birth } \\
\text { defects) }\end{array}$ & $\begin{array}{l}\text { No association between major } \\
\text { birth defects and exposure to } \\
\text { antidepressants }\end{array}$ \\
\hline Wisner et al. (2009) & SSRI & 71 & $\begin{array}{l}\text { No association between minor } \\
\text { and major birth defects and } \\
\text { exposure to SSRls }\end{array}$ \\
\hline Einarson et al. (2009) (2011) & $\begin{array}{l}\text { SSRI, bupropion, nefazodone, } \\
\text { trazodone, venlafaxine }\end{array}$ & 928 & $\begin{array}{l}\text { No association between exposure } \\
\text { to SSRIs and birth defects }\end{array}$ \\
\hline Einarson et al. (2011) & $\begin{array}{l}\text { SSRI, bupropion, nefazodone, } \\
\text { trazodone, venlafaxine }\end{array}$ & 1243 & $\begin{array}{l}\text { No association between exposure } \\
\text { to SSRIs and birth defects }\end{array}$ \\
\hline Kleiger-Grossman et al. (2011) & escitalopram & 212 & $\begin{array}{l}\text { No association between exposure } \\
\text { to escitalopram and birth defects }\end{array}$ \\
\hline
\end{tabular}

paroxetine was associated with atrial septal defects, omphalocele, and gastroschisis. Apart from the assessment of the teratogenic effect of paroxetine, the study also considered the safety profiles of four other SSRIs, including citalopram, escitalopram, fluoxetine and sertraline. 17952 mothers of children with birth defects were identified, and 9857 mothers who had given birth to healthy children in the years 1998-2009. Their use of SSRIs was confirmed based on a telephone interview, carried out 6 weeks to 2 years after delivery. The questions asked did not refer to depression specifically, but only to the medications taken from 3 months prior to pregnancy up to the moment of delivery. Only those women who admitted to having used an SSRI at least once in the period from 1 month prior to conception up to the third month of gestation were included in the study. Lack of exposure to SSRIs was defined as not using them in the period starting from 3 months prior to conception to the end of pregnancy, with no diagnosis of depression, anxiety, bipolar affective disorder, and obsessive-compulsive disorder at the time. Due to the documented teratogenic effect, the analysis excluded diabetic patients as well as women on selected medications, including misoprostol, methotrexate, mycophenolate mofetil, thalidomide, and isotretinoin. The final analysis included 17293 non-exposed children with birth defects, 659 exposed children with birth defects, 9559 non-exposed healthy children (control group) and 298 exposed healthy children (control group). The study results indicated that apart from paroxetine, also fluoxetine use in the first trimester of pregnancy was associated with the highest risk of congenital defects. Children exposed to fluoxetine during the first trimester were diagnosed with statistically significantly more atrial septal defects, right ventricular outflow tract obstruction, and craniosynostosis. Importantly, right ventricular outflow tract obstruction in children whose mothers were on fluoxetine or paroxetine in early pregnancy had previously been reported [20]. Additionally, cases of anencephaly [19] and atrial septal defects [21] had been reported following exposure to paroxetine.

An important finding from the above-mentioned study was the confirmation of a lack of association between sertraline use and anencephaly, anal atresia, septal defects, omphalocele and any limb reduction. Interestingly, as much as $40 \%$ of the respondents pointed out the use of that medication during pregnancy. Moreover, no association between maternal use of citalopram and escitalopram and ventricular septal defects, cleft lip with or without cleft palate, hypospadias, septal defects, except for a nonsignificant association between citalopram and neural tube defects, was found [13].

On the other hand, in a population-based cohort study, in which the safety of sertraline use in the first trimester of pregnancy was analysed based on the data collected from 18.5 thousand women, it was demonstrated that the risk of giving birth to a child with atrial or ventricular septal defect increased by $34 \%$, and the risk of craniosynostosis doubled [22].

In other studies, escitalopram was found to be linked with lower birth weight, but no such association was demonstrated for birth defects [23]. Individual cases of arhinia [24] 
and necrotising enterocolitis [25] were described in the newborns exposed to prenatal escitalopram. Still, a great majority of the available studies demonstrate no association between birth defects and escitalopram used during pregnancy [26].

A study based on the EUROCAT register (European Surveillance of Congenital Anomalies), including data on 2.1 million births in the years 1995-2009, demonstrated a link between the use of SSRIs in the first trimester of pregnancy and an increased risk of congenital heart defects (including tetralogy of Fallot, ToF). No differences were observed in terms of the teratogenic potential of the different SSRIs under analysis. However, the incidence of non-cardiac defects was found to be variable, depending on the medication used. Gastroschisis was found to correspond with most SSRIs, with the exception of paroxetine. Renal dysplasia was more common in children born to mothers on fluoxetine, and hypospadias was most strongly correlated with citalopram. Congenital lower limb deformity was associated with exposure to paroxetine, sertraline and escitalopram [27].

However, metanalysis of prospective cohort studies, published in 2015, found no association between SSRI use in the first trimester and heart defects [28].

An analysis involving a small group of patients (77) indicated that the use of venlafaxine, an antidepressant whose toxicity profile is similar to SSRIs, was associated with an increased risk of birth defects such as anencephaly, cleft palate, gastroschisis, and atrial septal defects, among others [29]. A cohort study carried out in the populations of Nordic countries (Denmark, Finland, Iceland, Norway and Sweden), based on a national health registry run in 1996-2010, also provided alarming data on the use of venlafaxine and SSRIs in the first trimester of pregnancy. The study group involved 2.3 million women in childbirth, with the group of siblings including 2288 live births. The analysed siblings constituted a group of children born to the same mothers. During at least one of those pregnancies, there was exposure to the study drugs, and birth defects were found in at least one of the siblings. The use of SSRIs or venlafaxine was confirmed based on a prescription filled within 30 days before the first day of the last menstruation up until the end of the first trimester of pregnancy ( 97 days following the last menstruation). The study aimed at determining the incidence of congenital heart defects. Other risk factors were also examined, including maternal age at delivery, calendar year of birth, number of prior births, smoking during pregnancy, gestational diabetes, and the use of others drugs. Out of the $\mathbf{3 6 7 7 7}$ newborns exposed to SSRIs or venlafaxine in the early phases of foetal life, birth defects were found in 1357 (3.7\%) of them, as compared with 71374 (3.2\%) from the non-exposed group (OR - 1.13,95\% Cl 1.06-1.20). The siblings analysis demonstrated that the risk of the analysed birth defects was $1.06 \%$ (95\% Cl 0.91-1.24). Taking into consideration cardiovascular defects only, the risk for the entire study group and the group of siblings was $1.5 \%$ (OR - 1.15, $95 \% \mathrm{Cl} 1.05-1.26)$ and $1.2 \%(\mathrm{OR}-0.92,95 \% \mathrm{Cl} 0.72-1.17)$, respectively. A detailed analysis of the cardiovascular defects indicated that all of the studied antidepressants, with the exception of escitalopram, increased the risk of cardiac defects, when used in pregnancy.

Another antidepressant, bupropion, is used to treat depressive disorders and as a smoking cessation aid. Most of the data on the impact of bupropion on the developing foetus comes from the Bupropion Pregnancy Registry database, established by the drug's producer. In a 2008 report, 24 cases of birth defects were described among children born to 675 women who had been on bupropion in the first trimester of pregnancy [30]. 9 cases of congenital heart defects were found, including ventricular septal defects and coarctation of the aorta ( 2 cases). Analysis of the results generated in the CDC's National Birth Defects Prevention Study (NBDPS) demonstrated no association between the use of bupropion and atrial septal defects, but it did confirm a slight increase in the risk of cardiovascular malformations, including coarctation of the aorta and hypoplastic left heart syndrome (HLHS) [31]. However, the findings were not confirmed in an analysis based on the Pregnancy Health Interview Study, which only pointed out a slight increase in the risk of ventricular septal defects in children born to mothers on bupropion in the first trimester of pregnancy [32].

Analysis of the Medicaid database, including data on nearly 950 thousand pregnancies (from the years 2000-2007), failed to demonstrate an association between the use of antidepressant medications (SSRIs, SNRIs, TCAs and bupropion) and birth defects, including congenital cardiac anomalies. On the other hand, the study indicated that women suffering from depression were significantly more frequently subjected to check tests such as ultrasound, foetal echocardiography, and amniocentesis than healthy women, which should be conducive to detecting even minor birth defects [33].

\section{ADVERSE EFFECTS OF ANTIDEPRESSANTS OTHER THAN BIRTH DEFECTS REPORTED IN CHILDREN WITH PRENATAL EXPOSURE Poor neonatal adaptation syndrome (PNAS)}

PNAS is a transient syndrome involving a set of symptoms that develop in response to foetal exposure to psychotropic medications. Aetiology of the syndrome has not been fully explored, though. It is emphasised that its symptoms, resembling those of withdrawal syndrome, may occur as a result of discontinued exposure to the drug upon birth (all psychotropic drugs cross the placental barrier). It has been noted that the syndrome does not develop in children born 
to mothers who take the same antidepressant drug during pregnancy and lactation. The PNAS symptoms involve weakened suction reflex, irritability, poor muscle tone, weak cry or lack thereof, sleep disturbances, hypoglycaemia, and seizures. In most cases, the symptoms appear within the first 8 hours of delivery and persist for the first 2-6 days of life. It is believed that the syndrome will not develop if there are no symptoms within the first two days of life [34]. Withdrawal symptoms and toxicity symptoms are largely overlapping, which is why differentiation based on the clinical picture is extremely difficult. Nevertheless, in case of toxic events, the symptoms emerge immediately upon delivery, and the drug's concentration in the newborn's serum is high. Withdrawal symptoms, on the other hand, appear within 8 to 48 hours of birth, and the drug serum level is low. Many researchers suggest a mixed aetiology of the syndrome, involving both elements of toxicity and withdrawal. An analysis of PNAS cases among mothers treated with antidepressants indicated an increase in the risk of respiratory distress and tremor. The analysis was inconclusive as to which of the drugs is associated most strongly with the risk of PNAS in newborns, but it was established that the symptoms may affect from $20 \%$ to $77 \%$ of children exposed to SSRIs during foetal life [35]. Some of the studies also indicated an increased risk linked to the use of paroxetine and fluoxetine [36]. When using venlafaxine, the risk of PNAS is comparable to that associated with the use of SSRIs [37].

In children with prenatal exposure to TCAs, individual cases of adverse events have been observed, including ischuria and constipation, stemming from the drugs' cholinolytic action. It is estimated that PNAS develops in $20-50 \%$ of children whose mothers receive TCAs during pregnancy [38]. Long-term effects of PNAS have been examined by a few observational studies only. No impact of PNAS on the children's IQ and general development has been reported [39].

\section{Persistent pulmonary hypertension of the newborn}

It is estimated that the incidence of the persistent pulmonary hypertension of the newborn (PPHN) amounts to $1.9 / 1000$ live births [40]. The symptoms are observed immediately upon delivery, and they may be of varying intensity, ranging from mild respiratory insufficiency to severe respiratory failure, leading to hypoxia, and requiring intensive medical care. In 2006, FDA published an alert, informing about the possible association between PPHN and prenatal SSRIs. In 2011, it was revised to include information on an insufficient number of findings, often contradictory, which made it impossible to draw unequivocal conclusions on the matter. In a meta-analysis published in 2014, it was indicated that the risk of PPHN was higher only in the case of SSRI use in advanced pregnancy (weeks 33-34) [41].

\section{SUMMARY}

In light of the available data, pregnancy should be well planned by women suffering from depression. Effective treatment of depression during pregnancy needs an obstetrician's and a psychiatrist's coordinated care. There are currently no recommendations as for the pharmacological treatment of depression in pregnancy. Each pregnant woman on antidepressants should thus be under continuous care of a specialised psychiatrist. Both modification of antidepressant treatment as well as its discontinuation (in particular discontinuation of paroxetine) should be consulted with the attending psychiatrist. Antidepressant medications should be discontinued gradually in order not to risk the appearance of withdrawal symptoms. Despite the fact that some antidepressants (fluoxetine and paroxetine) have been linked to an increased risk of birth defects $[13,14,42]$, it should be remembered that depression is a disease which is associated with a high risk of suicide, which is why the decision on discontinuing the treatment should take into consideration the patient's mental state. Moreover, some of the studies resulting in alarming findings on the teratogenic effect of antidepressant medications have failed to take into account other risk factors such as maternal age, and use of other drugs and stimulants. It is worth emphasising that the treatment of depression also involves psychotherapy, which is a recognized and recommended therapeutic method in pregnancy. Children born to mothers who used antidepressants during pregnancy should be under special medical surveillance, including comprehensive diagnostics of congenital anomalies (and cardiac defects in particular), and should be followed up for the risk of PNAS. It should also be remembered that depression during pregnancy increases the risk of postpartum depression. It should be stressed that more often the benefits for the mother exceed the potential risk for the neonate as a result of the use of antidepressants.

\section{REFERENCES}

1. Gavin NI, Gaynes BN, Lohr KN, et al. Perinatal depression: a systematic review of prevalence and incidence. Obstet Gynecol. 2005; 106(5 Pt 1): 1071-1083, doi: 10.1097/01.AOG.0000183597.31630.db, indexed in Pubmed: 16260528.

2. Byatt N, Deligiannidis KM, Freeman MP. Antidepressant use in pregnancy: a critical review focused on risks and controversies. Acta Psychiatr Scand. 2013; 127(2): 94-114, doi: 10.1111/acps.12042, indexed in Pubmed: 23240634

3. Gentile S. Untreated depression during pregnancy: short- and long-term effects in offspring. A systemic review. Neuroscience. 2015, S03064522(15)00811-8. doi: 10.1016/j.neuroscience.2015.09.001

4. Beydoun $\mathrm{H}$, Saftlas AF. Physical and mental health outcomes of prenatal maternal stress in human and animal studies: a review of recent evidence. Paediatr Perinat Epidemiol. 2008; 22(5): 438-466, doi: 10.1111/j.1365-3016.2008.00951.x, indexed in Pubmed: 18782252.

5. Buss C, Davis EP, Muftuler LT, et al. High pregnancy anxiety during mid-gestation is associated with decreased gray matter density in 6-9-year-old children. Psychoneuroendocrinology. 2010; 35 (1): 141-153, doi: 10.1016/j.psyneuen.2009.07.010, indexed in Pubmed: 19674845.

6. Farias DR, Pinto Td, Teofilo MM, et al. Prevalence of psychiatric disorders in the first trimester of pregnancy and factors associated with current 
suicide risk. Psychiatry Res. 2013; 210(3): 962-968, doi: 10.1016/j.psychres.2013.08.053, indexed in Pubmed: 24090486.

7. Yonkers KA, Wisner KL, Steward DE, et al. The management of depression during pregnancy: a report from the American Psychiatric Association and the American College of Obstetricians and Gynecologists. Obstet Gynecol. 2009; 114: 703-713.

8. Connolly KR, Thase ME. If at first you don't succeed. Drugs. 2011;71:43-64.

9. Chisolm MS, Payne JL. Management of psychotropic drugs during pregnancy. BMJ, 2015, 351: h5918.

10. Petersen I, Gilbert RE, Evans SJW, et al. Pregnancy as a major determinant for discontinuation of antidepressants: an analysis of data from The Health Improvement Network. J Clin Psychiatry. 2011; 72(7): 979-985, doi: 10.4088/JCP.10m06090blu, indexed in Pubmed: 21457681.

11. Cohen LS, Altshuler LL, Harlow BL, et al. Relapse of major depression during pregnancy in women who maintain or discontinue antidepressant treatment. JAMA. 2006; 295(5): 499-507, doi: 10.1001/jama.295.5.499, indexed in Pubmed: 16449615.

12. Zoega $H$, Kieler H, Nørgaard M, et al. Use of SSRI and SNRI Antidepressants during Pregnancy: A Population-Based Study from Denmark, Iceland, Norway and Sweden. PLoS ONE. 2015; 10(12): e0144474, doi: 10.1371/journal.pone.0144474, indexed in Pubmed: 26657647.

13. Reefhuis J, Devine O, Friedman JM, et al. National Birth Defects Prevention Study. Specific SSRIs and birth defects: Bayesian analysis to interpret new data in the context of previous reports. BMJ. 2015; 351: h3190, doi: 10.1136/bmj.h3190, indexed in Pubmed: 26156519.

14. Furu $\mathrm{K}$, Kieler $\mathrm{H}$, Haglund B, et al. SSRI and venlafaxine in early pregnancy and risk of birth defects: population based cohort study and sibling design. BMJ. 2015; 350: h1798.

15. Bałkowiec-Iskra E, Ryszewska-Pokraśniewicz B, Cessak G. Rola farmakoterapii i psychoterapii w leczeniu zaburzeń depresyjnych [English: The Role of Pharmacotherapy in the Treatment of Depressive Disorders]. Psychiatria po Dyplomie. 2013; 10: 41-45.

16. Sadler TW. SSRIs and heart defects: potential mechanism for the observed associations. Reprod Toxicol. 2011; 32: 484-489.

17. http://www.fda.gov/Safety/MedWatch/Safetylnformation/SafetyAlertsforHumanMedicalProducts/ucm152062.htm.

18. Bérard A, Ramos E, Rey E, et al. First trimester exposure to paroxetine and risk of cardiac malformations in infants: the importance of dosage. Birth Defects Res. B Dev. Reprod. Toxicol. 2007; 80(1): 18-27, doi: 10.1002/bdrb.20099, indexed in Pubmed: 17187388.

19. Alwan S, Friedman JM. Safety of selective serotonin reuptake inhibitors in pregnancy. CNS Drugs. 2009; 23(6): 493-509, doi: 10.2165/00023210200923060-00004, indexed in Pubmed: 19480468.

20. Louik C, Lin AE, Werler MM. First - trimestre use of SSRI and the risk of birth defects. N Engl J Med. 2007; 356: 2675-2683.

21. Bakker MK, Kerstjens-Frederikse WS, Buys $\mathrm{CH}$, et al. First-trimester use of paroxetine and congenital heart defects: a population-based case-control study. Birth Defects Res. Part A Clin. Mol. Teratol. 2010; 88(2): 94-100, doi: 10.1002/bdra.20641, indexed in Pubmed: 19937603.

22. Berard A, Zhao J, Sheehy $O$. Sertraline use during pregnancy and the risk of major malformations. Am J Obstet Gynecol. 2015; 212: 795 e. 1-12.

23. Klieger-Grossmann C, Weitzner B, Panchaud A, et al. Pregnancy outcomes following use of escitalopram: a prospective comparative cohort study. J Clin Pharmacol. 2012; 52(5): 766-770, doi: 10.1177/0091270011405524, indexed in Pubmed: 22075232

24. Majewski S, Donnenfeld AE, Kuhlman K, et al. Second-trimester prenatal diagnosis of total arhinia. J Ultrasound Med. 2007; 26(3): 391-395, doi: 10.7863/jum.2007.26.3.391, indexed in Pubmed: 17324992.

25. Potts AL, Young KL, Carter BS, et al. Necrotizing enterocolitis associated with in utero and breast milk exposure to the selective serotonin reuptake inhibitor, escitalopram. J Perinatol. 2007; 27(2): 120-122, doi: 10.1038/sj.jp.7211640, indexed in Pubmed: 17262045.

26. Bellantuono C, Bozzi F, Orsolini L, et al.The safety of escitalopram during pregnancy and breastfeeding: a comprehensive review. Hum Psychopharmacol. 2012;27(6):534-539, doi: 10.1002/hup.2265, indexed in Pubmed: 23044635.

27. Ban L, Gibson JE, West J, et al. Maternal depression, antidepressant prescriptions, and congenital anomaly risk in offspring: a population-based cohort study. BJOG. 2014; 121(12): 1471-1481, doi: 10.1111/14710528.12682, indexed in Pubmed: 24612301.

28. Wang S, Yang L, Wang L, et al. Selective Serotonin Reuptake Inhibitors (SSRIs) and the Risk of Congenital Heart Defects: A Meta-Analysis of Prospective Cohort Studies. J Am Heart Assoc. 2015; 4(5), doi: 10.1161/JAHA.114.001681, indexed in Pubmed: 25991012.

29. Polen K, Rasmusssen S, Riehle-Colarusso, et al. Association between reported venlafaxine use in early pregnancy and birth defects. National Birth Defects Research. 2013; 97: 28-35.

30. The Bupropion Pregnancy Registry. Final report. 1 September 2007 through 31 March 2008. Wilmington, NC, 2008

31. Alwan S, Reefhuis J, Botto LD, et al. National Birth Defects Prevention Study. Maternal use of bupropion and risk for congenital heart defects. Am. J. Obstet. Gynecol. 2010; 203(1): 52.e1-52.e6, doi: 10.1016/j. ajog.2010.02.015, indexed in Pubmed: 20417496.

32. Louik C, Kerr S, Mitchell AA. First-trimester exposure to bupropion and risk of cardiac malformations. Pharmacoepidemiol Drug Saf. 2014; 23(10): 1066-1075, doi: 10.1002/pds.3661, indexed in Pubmed: 24920293.

33. Huybrechts KF, Palmsten K, Avorn J, et al. Antidepressant use in pregnancy and the risk of cardiac defects. N. Engl. J. Med. 2014; 370(25): 23972407, doi: 10.1056/NEJMoa1312828, indexed in Pubmed: 24941178.

34. Levinson-Castiel R, Merlob P, Linder N, et al. Neonatal abstinence syndrome after in utero exposure to selective serotonin reuptake inhibitors in term infants. Arch Pediatr Adolesc Med. 2006; 160(2): 173-176, doi: 10.1001/archpedi.160.2.173, indexed in Pubmed: 16461873.

35. Oberlander TF, Misri S, Fitzgerald CE, et al. Pharmacologic factors associated with transient neonatal symptoms following prenatal psychotropic medication exposure. J Clin Psychiatry. 2004; 65(2): 230-237, doi: 10.4088/jcp.v65n0214, indexed in Pubmed: 15003078.

36. Kieviet N, Dolman KM, Honig A. The use of psychotropic medication during pregnancy: how about the newborn? Neuropsychiatr Dis Treat. 2013; 9: 1257-1266, doi: 10.2147/NDT.S36394, indexed in Pubmed: 24039427.

37. Boucher N, Koren G, Beaulac-Baillargeon L. Maternal use of venlafaxine near term: correlation between neonatal effects and plasma concentrations. Ther Drug Monit. 2009; 31(3): 404-409, doi: 10.1097/FTD.0b013e3181a58fb4, indexed in Pubmed: 19455083.

38. Stewart DE. Clinical practice. Depression during pregnancy. N. Engl. J. Med. 2011;365(17): 1605-1611, doi: 10.1056/NEJMcp 1102730, indexed in Pubmed: 22029982.

39. Klinger G, Frankenthal D, Merlob P, et al. Long-term outcome following selective serotonin reuptake inhibitor induced neonatal abstinence syndrome. J Perinatol. 2011; 31(9): 615-620, doi: 10.1038/jp.2010.211, indexed in Pubmed: 21311497.

40. Walsh-Sukys MC, Tyson JE, Wright LL, et al. Persistent Pulmonary Hypertension of the Newborn in the Era Before Nitric Oxide: Practice Variation and Outcomes. Pediatrics. 2000; 105(1): 14-20, doi: 10.1542/peds.105.1.14.

41. Grigoriadis S, Vonderporten EH, Mamisashvili L, et al. Prenatal exposure to antidepressants and persistent pulmonary hypertension of the newborn: systematic review and meta-analysis. BMJ. 2014; 348: f6932, doi: 10.1136/bmj.f6932, indexed in Pubmed: 24429387.

42. Bałkowiec-Iskra E. Bezpieczeństwo stosowania wybiórczych inhibitorów wychwytu zwrotnego serotoniny w czasie ciąży [English: The Safety of SSRI Use in Pregnancy]. Psychiatr Pol. 2015; 49: 1113-1115. 